\title{
MODERN DIGITAL TECHNOLOGIES IN JURISPRUDENCE
}

\author{
Valeriya V. Kurnosova ${ }^{1}$ \\ Vitaly V. Kurnosov ${ }^{2}$
}

\begin{abstract}
Digital technologies are actively entering into social relations, including well-established state legal institutions. At present, digitalization has deeply penetrated into the field of legislative and law enforcement practice.

Keywords: digital technologies, legal regulation, law enforcement, realization of law, artificial intelligence, blockchain, Internet of things, legal regulation, postindustrial society
\end{abstract} The analysis of the main development directions of digital technologies and the areas of their "penetration" into jurisprudence using general scientific and special methods allowed the authors to identify the main directions and prospects for the implementation of the main digital concepts in legal practice. The authors of the paper take into account the interdisciplinary nature of the problems posed, which determined the bilateral nature of the study. The results of the study can be used in the field of conducting both general theoretical and informational research. They can also be applied as part of legal education programs.

\section{Introduction}

The intensive development of the information technology area determines the regulation of public relations not only with the help of law, but also with the help of these technologies. In addition, the role of digital technology as an instrument of legal regulation will increase. This circumstance determines the coexistence in the legal regime of the content of not only the norms of regulatory legal acts and court decisions, but also the technical capabilities and practice of applying technologies. The development of digital technology in jurisprudence

\footnotetext{
1 Kazan Federal University, 18 Kremlyovskaya St., Kazan, Republic of Tatarstan, 420008, Department of Theory and History of State and Law. e-mail: VaVKurnosova@kpfu.ru. Tel. : +79375295322 ,

${ }^{2}$ Kazan State Technological University, 68 K. Marks St., Kazan, Republic of Tatarstan, 420015, Department of Technology of Polymers and Conversion of Compositional Materials. e-mail: vitaly99@mail.ru. Tel. : +79872221369.
} 
allows regulating and optimizing a number of legal procedures and even eliminating the violation of law. There is a need for the admissibility and legitimacy of the adaptation of digital technologies to jurisprudence and their compliance with the needs of the modern material world. [1]

\section{Methods}

The purpose, objectives and research methodology involve the use of various ways and methods of scientific knowledge. Analysis, synthesis and analogy make it possible to study the structure and content of information technologies, and their implementation in jurisprudence. Their complex interaction is carried out in the framework of the implementation of the structural-functional method. When carrying out the research, the authors used a complex of methods, including the evolutionary and dialectic research method, the target-oriented, systemic methods, the comparison method, analysis and synthesis, induction and deduction. General methodological principles are the principles of historicism, scientific character and objectivity. Private research methods are determined by the foundations of the principle of consistency applied by the authors.

\section{Results And Discussion}

Modern processes, in particular, legal regulation, seem almost impossible without the widespread adoption and use of modern digital technologies, which allow us to implement many diverse tasks in a short time.

Artificial intelligence, blockchain, virtual assistants, neural networks, virtual reality and the Internet of things stand out among the main theses regarding the development of future digital technologies,.

In the definition of artificial intelligence as an achievement of technical progress, there is some fuzziness of concepts, since it includes the results of technical developments in various fields, such as robotics, recognition of phenomena, and algorithmization of processes. The problem of the lack of a legal definition for the term "artificial intelligence" is noted in the literature, while in science there are about fifteen of its naturalscientific definitions. 
At present, the acute problem is the almost complete absence of statutory regulation and technical regulation concerning the basics of the artificial intelligence use. At the same time, approaches to legal regulation depend on how to understand artificial intelligence: as an object of legal relations or as a subject of legal relations.

Currently, artificial intelligence systems constitute a specific object of legal relations, since they are an anthropogenic product and cannot be anything more than a property of people.

Among the possible prospects for the legal regulation of artificial intelligence, the possibility of creating a special legal regime applicable to such systems and the allocation of a special "electronic subject" of legal relations is justified. This is due to the fact that artificial intelligence is actively used in various legal relations related to transport, educational, medical, financial services, which gives rise to certain legal consequences. In addition, there is likelihood that the actions of artificial intelligence can cause damage and be unlawful. So, in Tampa (Arizona, USA), an unmanned vehicle hit a pedestrian during the tests. Quite justifiably, the question arises of who or what will be punished in this case and in what form. Currently, developers of artificial intelligence are responsible for the harm caused by its bearer; however, this postulate is increasingly debatable.

In some countries (Saudi Arabia, Belgium) precedents exist for giving artificial intelligence the status of a subject of law and even citizenship.

At the same time, artificial intelligence has great potential and prospects for application in all spheres of human life, including in the field of legal process and legal regulation. [2]

The blockchain is a dispersed database (a chain of blocks), the storage devices of which are not connected to a common server, with each element containing a temporary clue and a link to the previous block. [3]

The use of this technology has caused an active development of smart contracts, the execution of which is carried out automatically subject to all conditions. The big advantage of these contracts is their efficiency and data reliability [4].

In addition, they highlight the prospects for using this technology in distributed ledgers for property rights. 
Thus, the register of rights to real estate will allow us to create and implement a chain of "legal life" of property. A similar system is possible with the regulation and protection of intellectual property rights. Information will be in the public domain, which will track any changes and all recorded documents.

Virtual assistants help to significantly reduce staff costs and optimize supporting routine processes. Virtual assistants are engaged in sending messages and letters at certain stages of legal procedures (notification of the readiness of documents, notification of the stages of the trial) [5]. In addition, virtual assistants are actively used in the "E-justice" and "Public services" systems actively used in Russia by analysing downloaded documents and prompting further actions to participants in the legal process at all its stages.

We can distinguish the Intraspexion system also, which analyses the business correspondence of participants in legal relations, suggests the desired language and thereby prevents, as its creators claim, potential litigation.

The Legal Robot system is able to analyse any contract for compliance with regulatory legal acts and codes stored in its memory using statistical techniques and machine learning.

In addition, it is worth highlighting the development of robot programs that analyse incoming information from users and transmit a will in cases when a person gives his/her consent in advance, that is, all incoming letters with an offer to conclude a contract for all possible letters with offers to conclude a contract or acceptance of public offer agreements. Robot programs automatically change the seller's offer to sell goods on the seller's website, adjusting them in real time taking into account the availability of goods in the warehouse, currency exchange, and make it possible to quickly correct errors.

Neural networks are increasingly demonstrating all their benefits in jurisprudence. So, for example, currently there are technologies that allow us to calculate the time duration of a trial and predict its outcome, while the system includes judicial decisions on similar and analogues cases.

Neural networks are active assistants during the trial [6]. For 


\section{Sichiere}

example, until recently, in the course of litigation on copyright infringement on a musical work, the conclusion of a musicologist was required. Currently, the analysis of musical works in the event of a dispute regarding their similarity is sufficient to carry out using the technology of the Shazam system. In addition, it should be noted and the development of the Dare network, which will recognize false testimony based on facial expressions, voices and gestures of the suspect and witnesses.

Big data is a technology that allows us to simultaneously process new incoming data, work with them, including structuring them in accordance with various aspects. These services are actively used in modern jurisprudence, existing in the form of legal reference systems, services for the search and analysis of court cases, as well as in electronic document management systems, including for interagency interaction [7].

In addition, the Big Data algorithm is planned to be introduced into legal practice to automate the search for legal conflicts and legal gaps in a large array of state laws. In common law countries, such a system already exists.
In addition, the ROSS system which analyses the existing array of judicial practice and legislation, as well as the Lex-Machina system, which analyses the judicial practice of different states and offers lawyers the most "convenient" jurisdiction to resolve the dispute, should be highlighted.

The Internet of things (IoT Internet of Things) is a network for computing objects of "things" equipped with this technology for interacting objects with each other or with the external environment capable of building social processes without human intervention [8].

This concept is manifested in projects such as automated parking, unmanned vehicles, as well as payment of fines and state fees via the Internet, participation in the municipal survey through the portal of state municipal services and others.

In addition, the Internet of Things is involved in "video analytics" and real-time image processing. For example, face recognition technology is actively used in a number of countries (for example, in China) to search for persons who have committed an offense. Cameras installed in public places, for a 
couple of seconds, check the appearance of all passers-by with the information of the police database and, if a match is found, signals this to the law enforcement officer.

A relevant area for IoT technologies application is the Smart City system. In particular, the "Smart City" is used to improve relations between urban residents and the state, to optimize and improve the quality of municipal and state services and the work of law enforcement agencies and public organizations [9].

\section{Summary}

Thus, information technology, actively penetrating into public life, is increasingly being introduced into legal practice. Information technology will inevitably penetrate the field of law enforcement and legal regulation. In addition, the digitalization of law affects legal practice as a whole, determining the tendency to automate certain legal functions [10].

Already today, in a number of states the so-called technological unemployment is being discovered. It is necessary to resolve these issues by introducing new legislation related to digital legal relations, in particular, regulating the status of artificial intelligence.

Thus, the formation of mechanisms in the field of artificial intelligence, the emergence of new areas of methods and structures in the field of legal regulation, its digitalization should be noted as the most important areas in the field of law.

Responsibilities of artificial intelligence and virtual assistants require the search for legislative solutions. As a result of their failure, the actions of malicious programs, a power surge, the behaviour of a digital subject with a given algorithm is likely to diverge, which can lead to adverse consequences and violations of the rights and freedoms of people around, which justifiably raises the question of responsibility for such an act.

\section{Conclusions}

The rapid development of digital technology did not go unnoticed in jurisprudence and legal practice. There is an increasing need for a legal settlement and determination of the status of artificial intelligence as a participant in legal relations; there is a 
need to introduce blockchain

18.-

No.

4.-Pp.

technologies into the legal life to create open and transparent registries. The role

Robot Law / eds. by R. Calo, A. M. of virtual assistants in the mechanisms of law enforcement and administration of Froomkin, I. Kerr. Cheltenham, -2016.P.324.;

the law is also growing, there is an active introduction of neural networks and a big data system in legal practice; the Internet of things is being actively used to ensure open and operational interaction between citizens and the state.

It is important to note that the problems of regulating relations concerning information technology are devoid of industry affiliation and require a systemic intersectoral and interdisciplinary approach.

\section{Acknowledgements}

The work is performed according to the Russian Government Program of Competitive Growth of Kazan Federal University.

\section{References}

Chesnokov A.A. Internet Resources and Russian Political Technologies: State and Development Prospects // Moscow State University Bulletin. -1999. - Series

Mark A. Beyer, Douglas Laney. The Importance of «Big Data»: A Definition.-2012. -P.34.; 
Efroni Z. Access-Right: The Future of

Digital Copyright Law. - Oxford

University Press. - 2013.- P. 8;

Gyaro T. From the modern SOFT LAW

to the antique SOFT LAW //

Jurisprudence. 2016. -№ 2. - Pp.78-79. ;

Tereshchenko L.K. Riddles of

information law // Journal of Russian

Law. - 2017.- №7.-P.161 